\title{
MEMBANGUN SPIRITUAL WELL-BEING PELAKU UMKM DI JAMBI DI ERA PANDEMI COVID 19
}

\section{Raja Oloan Tumanggor ${ }^{1}$, Fransisca I.R. Dewi ${ }^{1}$ dan Hotnida Nethania Agatha ${ }^{1}$}

\author{
${ }^{1}$ Fakultas Psikologi, Universitas Tarumanagara Jakarta \\ Email: rajat@fpsi.untar.ac.id
}

\begin{abstract}
This article is the result of training for 4 micro, small and medium businesses in Jambi who are having problems managing their businesses as a result of the Covid 19 pandemic. The training aims to inspire small and medium business actors to continue their business, carried out through zoom with the lecture method, ask questions, and share experiences. The problems they face include lack of customers, declining turnover, which results in decreased income as well. However, various attempts have been made to get rid of this problem. One aspect that can help them rise from adversity is to build spiritual well-being by fostering harmonious relationships with themselves, others, the natural environment and God. Spiritual well-being is not only about a relationship with divine power, but also about a good relationship with oneself, others, and the universe. A person is called spiritually prosperous if he is able to be honest with himself, see the positive in others, maintain the universe and be obedient to worship. All these aspects need to be owned by every business actor. Through real spiritual well-being from the emergence of self-confidence, optimism, and the ability to surrender to God's power, they are then able to see various opportunities that can be done to continue their business such as opening a business in other fields, and changing marketing methods. The important thing is that they can survive even in the difficult atmosphere of the pandemic era.
\end{abstract}

Keywords: training; pandemic; spiritual well-being; micro small and medium businesses

\begin{abstract}
ABSTRAK
Artikel ini merupakan hasil pelatihan terhadap 4 orang pelaku UMKM di Jambi yang mengalami masalah dalam mengelola usahanya sebagai dampak dari pandemi Covid 19. Pelatihan yang bertujuan membangkitkan semangat para pelaku usaha kecil dan menengah melanjutkan usahanya, dilakukan melalui zoom dengan metode ceramah, tanya jawab, dan sharing pengalaman. Masalah yang mereka hadapi antara lain kurangnya pelanggan, omzet menurun, yang berakibat pada pendapatan yang menurun juga. Namun berbagai upaya dilakukan untuk bisa lepas dari persoalan itu. Salah satu aspek yang bisa menolong mereka bangkit dari keterpurukan itu adalah dengan membangun kesejahteraan spiritual dengan cara membina relasi yang harmonis dengan diri sendiri, sesama, alam lingkungan dan Tuhan. Kesejahteraan spiritual bukan hanya menyangkut soal relasi dengan kekuasaan ilahi, tetapi juga menyangkut relasi yang baik dengan diri sendiri, sesama, alam semesta. Seseorang disebut sejahtera secara spiritual bila mampu jujur terhadap diri sendiri, melihat yang positif dalam diri sesama, memelihara alam semesta dan taat beribadah. Semua aspek tersebut perlu dimiliki oleh setiap pelaku usaha. Melalui kesejahteraan spiritual yang nyata dari munculnya kepercayaan diri, optimisme, dan kemampuan berserah kepada kekuasaan Tuhan, mereka kemudian mampu melihat berbagai peluang yang bisa dilakukan untuk melanjutkan usahanya seperti membuka usaha di bidang lain, dan merobah metode pemasaran. Yang penting mereka bisa bertahan kendati dalam suasana sulit di era pandemi.
\end{abstract}

Kata kunci: pelatihan; pandemi; kesejahteraan spiritual; pelaku UMKM

\section{PENDAHULUAN}

Pandemi Covid 19 membawa dampak dalam segala bidang kehidupan manusia. Secara khusus yang paling berdampak adalah pada bidang kesehatan dan ekonomi. Hal ini dialami hampir di seluruh dunia termasuk Indonesia. Di bidang ekonomi dampak pandemi ini dialami seluruh sektor baik pengusaha besar maupun kecil. Para pengusaha lapisan bawah seperti pelaku usaha mikro kecil dan menengah (UMKM) mengalami berbagai persoalan yang cukup rumit. Salah satu kelompok yang menjadi pusat perhatian lembaga pendidikan seperti Universitas Tarumanagara adalah pelaku UMKM yang ada di Provinsi Jambi. Dampak pandemi ini tentu dialami oleh para pelaku UMKM. Pemerintah daerah Jambi melalui berbagai upaya, salah satunya dinas koperasi UMKM berupaya menolong mereka dengan memberikan penyuluhan dan bantuan (Dinas Koperasi Propinsi Jambi, 2021). 
Dalam upaya turut membantu pelaku UMKM Propinsi Jambi, selama beberapa bulan di tahun 2021 para dosen yang berasal dari berbagai fakultas melakukan kegiatan Pengabdian Kepada Masyarakat (PKM) kepada para pelaku UMKM khususnya yang ada di kota Muaro Jambi dan sekitarnya.

PKM yang dilakukan oleh para dosen dari Fakultas Psikologi umumnya mencoba mendampingi para pelaku usaha dalam menghadapi situasi kurang menguntungkan di saat pandemi sekarang ini. Tentu pendekatan yang dilakukan kepada para pengusaha kecil ini adalah berupa psikoedukasi dan pendampingan secara psikologis, sehingga mereka mampu menghadapi situasi sulit tersebut.

Persoalan yang umumnya mereka hadapi adalah menurunnya pelanggan dalam penjualan produk hasil usaha mereka. Penurunan permintaan ini tentu berakibat kepada menurunnya penghasilan. Penurunan penghasilan menyebabkan mereka kesulitan untuk membayar biaya operasional dan para karyawan yang selama ini mereka rekrut terpaksa dirumahkan. Jangankan mengelola usaha kecil yang mereka rintis, kebutuhan harian pun kadang mengalami kesulitan.

Pendampingan yang dilakukan oleh para dosen psikologi tentu bukan mau mencari solusi bagaimana meningkatkan produksi atau keknik apa yang bisa dilakukan di saat ekonomi mengalami kelesuan, tetapi berusaha mendampingi mereka secara psikologis. Tujuannya adalah agar mereka mampu berdamai dengan kondisi yang mereka hadapi sehingga mereka bisa bertahan untuk menjalankan usahanya kendati berhadapan dengan banyak rintangan dan kesulitan.

Salah satu upaya yang ditawarkan oleh dosen psikologi adalah bagaimana caranya para pelaku UMKM ini bisa bangkit kembali dari keterpurukan dengan memperhatikan faktor spiritualnya. Dengan kata lain, bagaimana caranya membangun kesejahteraan spiritual para pelaku UMKM sehingga mereka bisa bangkit dari situasi sulit tersebut? Dalam menghadapi kondisi yang kurang menguntungkan bagi pelaku UMKM di era pandemi Covid 19 banyak faktor yang harus diperhatikan agar bisa survive. Selain faktor psikologis, juga faktor spiritual (kerohanian) memiliki peranan penting. Maka perlu membangun kesejahteraan spiritual (spiritual well-being) bagi para pelaku UMKM agar bisa tangguh menghadapi segala kesulitan di masa pandemi sekarang ini.

Apakah spiritual well-being itu dan bagaimana kita membangun atau meningkatkan kesejahteraan spiritual kita dalam menghadapi kondisi sulit para pelaku UMKM di masa pandemi sekarang ini? Kata spiritual well-being berarti kesejahteraan spiritual. Jadi kata spiritual berasal dari kata Latin spiritus yang artinya roh. Spiritual well being merupakan kondisi sejahtera secara spiritual yang dialami oleh seorang individu, sebab ia dapat menghayati nilai-nilai relasi dengan Tuhan yang diyakini dalam hidupnya. Menurut J.W. Fisher (2010) spiritual well- being adalah afirmasi hidup dalam berelasi dengan diri sendiri, komunitas, lingkungan, dan Tuhan. Relasi itu kemudian dikembangkan dalam empat domain/dimensi yang saling berkaitan. Keempat domain itu meliputi pertama, domain personal, dimana seseorang berhubungan dengan diri sendiri menyangkut makna, tujuan dan nilai dalam hidup. Kesadaran ini menjadi kekuatan yang menentukan dari roh manusia dalam mencari identitas diri. Kedua, domain komunal nampak dalam kualitas dan kedalaman relasi interpersonal antara diri sendiri dengan orang lain. Relasi ini diungkapkan dalam cinta, pengampunan, kepercayaan, harapan dan iman. Ketiga, domain lingkungan menyangkut pemeliharaan fisik dan biologis, rasa memiliki dan kagum serta gagasan kesatuan dengan lingkungan. Keempat, domain transendental meliputi hubungan diri sendiri dengan sesuatu yang melewati aspek manusia, seperti kepedulian pada kekuatan kosmis dan realitas transenden (Fisher, 2011; Fisher \& Ng, 2017). 
Spiritual well-being memang berkaitan dengan religiositas, tapi tidak sama. Religiositas lebih menekankan pada pelaksanaan ajaran-ajaran dogma keagamaan tertentu, sedangkan spiritual well being mampu menumbuhkan kesadaran diri sebagai makhluk transenden yang mempunyai tujuan dan makna dalam kehidupannya selama ia tinggal di muka bumi. Setiap manusia diciptakan oleh Tuhan dengan maksud dan tujuan mulia, yaitu setiap manusia harus menyadari akan eksistensi dirinya. Setiap kehidupan yang dihidupinya, setiap orang harus dapat mencari dan menemukan makna hidupnya (Maran, 1996).

\section{HASIL DAN PEMBAHASAN}

Kegiatan ini dilakukan secara daring melalui media Zoom meeting. Setelah pemaparan materi dari fasilitator dilanjutkan dengan sesi sharing bersama para peserta. Dalam pemaparannya mengenai cara membangun kesejahteraan spiritual bagi para pegiat UMKM, fasilitator menjelaskan empat dimensi kesejahteraan spiritual, yaitu: (1) Hubungan dengan diri sendiri (domain personal), berkaitan dengan diri sendiri, pencarian makna pribadi, pencarian tujuan dan nilai-nilai kehidupan. Domain pribadi ini berkaitan dengan kesadaran diri, yaitu kekuatan pendorong jiwa manusia untuk mencapai identitas dan harga diri, aspeknya: makna, tujuan, nilai-nilai, kesadaran diri, kegembiraan, perdamaian, kesabaran, identitas, dan nilai diri.

(2) Hubungan dengan orang lain (domain communal) berupa kualitas dan kemampuan interpersonalnya dengan tingkat kualitas lebih mendalam, menjalin hubungan dengan orang lain, berkaitan dengan moralitas dan budaya. Adanya kasih sayang, pengampunan, kepercayaan, harapan dan kemampuan mengaktualisasikan iman terhadap sesama, aspeknya: moral, kebudayaan, agama, kedalaman hubungan antar personal, pemaaf, keadilan, cinta dan kepercayaan. (3) Hubungan dengan lingkungan (domain environmental), berupa keterikatan terhadap lingkungan secara natural, kepuasan saat mengalami pengalaman puncak (peak experience), menikmati keindahan alam, kemampuan untuk memelihara lingkungan agar dapat memberi manfaat terhadap sekitar, aspeknya: mempedulikan, pekerjaan (mengurus), hubungan dengan alam, dan puncak pengalaman yang menimbulkan kekaguman. (4) Hubungan dengan Yang transenden (domain transcendental), kemampuan untuk menjalin hubungan dengan pencipta, melibatkan iman, pemujaan dan penyembahan terhadap realitas transenden yaitu Tuhan. Ada kepercayaan (faith) terhadap Tuhan aspeknya: kepentingan yang sangat pada transenden, kekuatan alam yang mengacu pada rasa yang melampaui ruang dan waktu, kekhawatiran yang sangat, keyakinan, penyembahan, dan ibadah (Fisher \& Gomez, 2002).

Setiap manusia dihadapkan pada situasi kehidupan yang serba belum pasti, namun semuanya tergantung pada masing-masing individu dalam menghayati kehidupannya. Seseorang dapat dihadapkan pada situasi yang sulit, sehingga ia diharapkan dapat melalui, menghadapi dan menyelesaikan situasi tersebut dengan baik. Menghindari situasi yang sulit bisa saja dilakukan oleh seseorang, namun hal itu tidak akan menyelesaikan masalah. Suatu saat pada waktu yang berbeda, ia akan dihadapkan kembali pada situasi sulit yang hampir sama taraf kesulitannya. Mau tak mau, ia harus dapat menyelesaikan hingga ia berhasil dapat mengatasi situasi tersebut dengan baik. Seseorang yang mempunyai spiritual well being yang baik, maka ia sadar akan situasi sulit yang harus dihadapinya. Ia tidak akan mengeluh, menyerah atau putus asa dalam situasi tersebut. Ia justru merasa bersyukur atas situasi yang harus dihadapinya, sebab hal itu akan meningkatkan karakteristik pribadi yang tangguh, kuat dan tahan banting. Dalam situasi yang sulit, seseorang dituntut untuk mampu mengatasinya dengan baik. Dengan demikian, ia akan mengembangkan kepribadian yang tangguh, kuat dan tahan banting (Mathad et al., 2017).

Upaya apa yang bisa dilakukan untuk membangun spiritual well-being? Perlu membenahi relasi yang baik dengan diri sendiri, dengan sesama, dengan alam lingkungan, dan dengan Tuhan (Yang 
Transenden). Manusia perlu memiliki relasi yang baik dengan keempat domain/dimensi ini dalam konteks pandemi yang menimbulkan bermacam masalah dalam kegiatan UMKM. Apakah itu bisa? Ya harus bisa. Setiap orang bisa melakukannya bila ada tekad bahwa segala kecemasan akan hilang disaat memiliki relasi baik dengan diri sendiri, sesama, alam dan Tuhan. Dengan cinta orang akan bisa berelasi dengan siapapun, misalnya: diri sendiri, sesama, alam lingkungan dan Tuhan.

Lalu bagaimanakah ciri-ciri orang yang sudah memiliki spiritual well-being yang baik? Kesejahteraan spiritual merupakan individu yang dalam kondisi makmur dari segala aspek, baik rohani, mental, keagamaan dll. Dimensi kesejahteraan spiritual personal, communal, environmental, dan transcedental merupakan kunci bagi setiap individu dalam pencarian makna dan tujuan hidup, sebab setiap domain memiliki keterikatan satu dengan yang lain. Keharmonisan empat domain tersebut akan memberikan individu kebahagiaan dan keselarasan hidup. Individu dikatakan sudah dalam keadaan sejahtera secara spiritual apabila mencakup ke empat domain tersebut. Karena Keempat domain yang telah dijelaskan di atas adalah hal yang sangat penting, domain-domain tersebut merupakan komponen yang membangun kesejahteraan spiritual secara total dan utuh. Ketika individu hanya memiliki domain transenden dan personal maka individu dikatakan mengalami spiritual disease (penyakit spiritual) karena terisolasi dari masyarakat dan meniadakan domain communal serta environmental.

Setelah selesai pemaparan dari fasilitator dilanjutkan dengan bagi pengalaman di antara para peserta dengan fasilitator. Ibu I adalah seorang pengusaha yang bergerak dalam produksi beras skala kecil. Kendala yang dihadapi oleh Ibu I adalah kurangnya referensi tempat untuk menyalurkan dalam skala besar, sehingga bisnis tidak berkembang. Ibu I berencana untuk mengembangkan produksi beras, ia berharap dapat menjangkau hingga luar kabupaten.

Ibu S adalah seorang pengusaha katering harian yang tinggal di Kota Jambi. Ia sudah menekuni bisnis katering ini hampir tiga tahun. Ibu $\mathrm{S}$ adalah seorang single parent, yang memiliki tanggungan orang tua dan anak. Ibu S menceritakan bahwa sebelum pandemi Covid-19, rata-rata yang memesan katering miliknya adalah para pelajar dan mahasiswa rantau. Namun semenjak pandemi dan adanya Pemberlakuan Pembatasan Kegiatan Masyarakat (PPKM), omset bisnis menurun drastis.

Sebagai upaya untuk menambah pemasukan, Ibu S juga sedang mencoba usaha di bidang fashion, seperti menjual pakaian, jilbab, dan lain sebagainya. Ibu S mengatakan bahwa barang-barang fashion ini sifatnya awet dan dapat disimpan lama, tidak seperti makanan yang tidak dapat disimpan lama. Sebagai seorang single parent, Ibu S merasa bertanggung jawab terhadap orang tua dan anaknya. Ibu S mengatakan bahwa dirinya akan melakukan apapun asalkan halal. Ia yakin dirinya mampu, dan percaya bahwa selama mau berusaha pasti akan diberikan jalan oleh Tuhan Yang Maha Esa.

Ibu A adalah seorang pengusaha yang tinggal di Muara Bungo. Bisnis Ibu A bergerak dalam bidang makanan dan minuman herbal, yaitu minuman jahe dan kunyit instan. Awalnya, Ibu A menggerakkan masyarakat di lingkungan sekitar untuk memanfaatkan pekarangan dengan budi daya jahe dan kunyit. Niat awal dari pembentukan kelompok tersebut adalah untuk membuat suatu usaha, namun ternyata tidak bertahan lama. Sehingga, usaha tersebut dilanjutkan oleh Ibu A atas nama pribadi.

Ibu A sudah menekuni bisnis ini selama kurang lebih 4 tahun. Bisnis Ibu A tidak terdampak pandemi Covid-19, bahkan banyak orang yang memesan jahe dan kunyit instan. Di lingkungan tersebut, hanya Ibu A yang membuat jahe instan yang benar-benar menggunakan jahe merah, 
sehingga permintaan tetap tinggi. Namun, sering kali pesanan tidak dapat diterima semua karena proses pembuatan yang masih manual dan keterbatasan sumber daya manusia.

Anggota yang dulu aktif, menjadi tidak aktif karena mempunyai kesibukan masing-masing. Proses pembuatan juga membutuhkan waktu yang lama sekitar 3-4 jam, sehingga sulit untuk mencari para pekerja. Adanya ketidakmampuan dalam memenuhi pesanan, serta proses pembuatan yang masih manual dan keterbatasan sumber daya manusia, membuat Ibu A belum bisa memasarkan produk ke pasar yang lebih luas.

Terdapat dua pesan yang ingin disampaikan oleh Ibu A kepada para pihak yang berwenang. Pertama, mengenai sertifikat halal. Kedua, berharap untuk dapat dibantu oleh pemerintah dalam peralatan usaha seperti alat untuk mengolah jahe, sehingga pengerjaannya bisa lebih cepat dilakukan dari pada cara tradisional/manual. Selain itu Ibu A juga berharap agar ada kemudahan dalam memperoleh alat transportasi untuk mengangkut produknya, karena jarak ke pasar yang lumayan jauh.

Bapak $\mathrm{H}$ adalah seorang pengusaha yang tinggal di Kota Jambi. Usaha Bapak H bergerak dalam bidang cucian karpet. Ia menceritakan bahwa semenjak pandemi melanda, bisnis yang ia jalani $80 \%$ macet. Hal yang memotivasi Bapak H untuk tetap semangat adalah anaknya perempuan yang saat ini memasuki semester 3 di FKIP Pendidikan Ekonomi, Universitas Jambi. Hal ini membuat Pak H tetap bersemangat menekuni usahanya agar anaknya bisa terus kulilah.

Dari sharing pengalaman ini jelas bahwa para pelaku UMKM mengalami persoalan yang berbedabeda dengan cara pemecahan yang berbeda juga. Namun, hal yang sama mereka miliki adalah optimisme dan keuletan untuk bisa bertahan dalam situasi yang sulit. Optimisme dan keuletan itu akan semakin meningkat dan bertahan lama bila dibarengi dengan kesejahteraan spiritual yang memadai.

\section{KESIMPULAN DAN SARAN}

Para pelaku UMKM memiliki pengalaman dan persoalan yang beragam di saat pandemi sekarang ini. Mereka tetap masih memiliki harapan dengan tetap berusaha kendati banyak tantangan yang menghimpit. Mereka berusaha melihat peluang lain yang bisa dilakukan untuk meminimalkan kerugian atau malah upaya apa pun dilakukan agar masih bisa bertahan untuk berusaha di masa pandemi. Mereka sepakat bahwa selain upaya teknis ekonomis yang harus mereka lakukan, mereka membutuhkan dukungan psikologis baik dari keluarga maupun dari pihak pemerintah. Selain faktor psikologis seperti resiliensi, optimisme dan kreativitas, mereka membutuhkan juga faktor non psikologis seperti kesejahteraan spiritual. Ternyata untuk membangun kesejahteraan spiritual ini tidak cukup hanya bidang pelaksanaan ibadah ritual keagamaan, tetapi juga penting untuk membangun relasi yang baik dengan diri sendiri melalui kepercayaan diri, membina relasi dengan sesama sebagai teman seperjuangan dalam berusaha, dan dengan alam/lingkungan hidup, tempat manusia berada. Relasi yang baik dan harmonis dengan keempat dimensi diri sendiri, sesama, lingkungan dan Tuhan menandakan seseorang memiliki kesejahteraan spiritual. Dan kesejahteraan spiritual ini menjadi modal penting dalam upaya mengatasi persoalan rumit yang dihadapi pelaku UMKM di Jambi pada masa pandemi.

\section{Ucapan Terima Kasih (Acknowledgement)}

Terimakasih disampaikan kepada LPPM Universitas Tarumanagara yang memungkinkan PKM ini terlaksana dengan baik. Terimakasih juga kepada para pelaku UMKM Jambi yang telah menjadi mitra yang baik selama pelaksanaan PKM. 


\section{REFERENSI}

Dinas Koperasi Propinsi Jambi (2021). Dinas koperasi dan ukm propinsi jambi. https://diskopukm.jambiprov.go.id/berita/index/category.html

Fisher, J.W. \& Gomez, R. (2002). Domains of spiritual well-being and development and validation of the Spiritual Well-Being Questionnaire, Personality and Individual Differences 35, 19751991.

Fisher, J.W. (2010). Development and application of a spiritual well-being questionaire called SHALOM. Religions, 1, 105-121.

Fisher, J.W. (2011). The Four domains model: connecting spirituality, health and well- being. Religions 2, 17-28.

Fisher, J.W. \& Ng, D. (2017). Presenting a 4-item spiritual well-being index (4- ISWBI). Religions $8,179$.

Maran, R. R. (1996). Manusia dan kebudayaan : dalam perspektif ilmu budaya dasar. Yayasan Akselerasi.

Mathad, M. D. et al. (2017). Spiritual well-being and its relationship with mindfulness, selfcompassion and satisfaction with life in baccalaureate nursing students: a correlation study, Journal for Religious Health, 58(2), 554-565. DOI: 10.1007/s10943-017-0532-8. 